\title{
A noble prize
}

\section{The 2009 Nobel Prize in Chemistry will soon be awarded amid the usual speculation, angst, disagreement and elation - but is it really worth all the fuss?}

Imagine a world where Christmas comes once a year, but only to one, two or three boys or girls who have been especially good. All the other well-behaved children receive no gifts, and those lucky few who were chosen become the centre of attention and no longer have time to do the chores that led to them being picked out in the first place. Not to mention that some of the other children are now a little jealous of the presents and the attention bestowed on their former playmates. Wouldn't that be a shame?

Of course, many more children are given Christmas presents every year, but the Nobel Prize Committee cannot be so generous. The rules of the Nobel Foundation - the private institution that administers the award of the Nobel Prizes - stipulate that each prize can be awarded to only one, two or three individuals.

Alfred Nobel's will also stated that the prizes should recognize work done 'during the preceding year', and although 'fresh' discoveries were recognized in the early days of the prizes, today there is often a substantial time lag between a discovery and the phone call from Stockholm. Nowadays, it is generally the case that only discoveries that have passed years of experimental scrutiny are rewarded. Indeed, when playing the 'guess the next laureate' game, one tactic is to consider work that is so accepted, and in so many text books, that people have forgotten that someone had to actually perform the experiments that led to the discovery.

Alfred Nobel made his great fortune as an industrial chemist, with inventions in weapons technology beyond just dynamite. He bought Bofors, which he shaped into the armament manufacturer that it still is today $^{2}$, albeit in a different form. Conversely, he also attempted to buy a Swedish evening newspaper, in order to "use its influence against armaments". In this, and the establishment of the prizes that now bear his name, was Nobel trying to atone for the blood shed by his discoveries? Albert Einstein (Physics, 1921) said as much, in a speech after the use of the terrible weapon that he had been instrumental in creating.

Einstein's Nobel Prize was not a controversial one, but the fact that he received only one has been debated at length - as have many other awards. Much of this stems from limiting the number of recipients

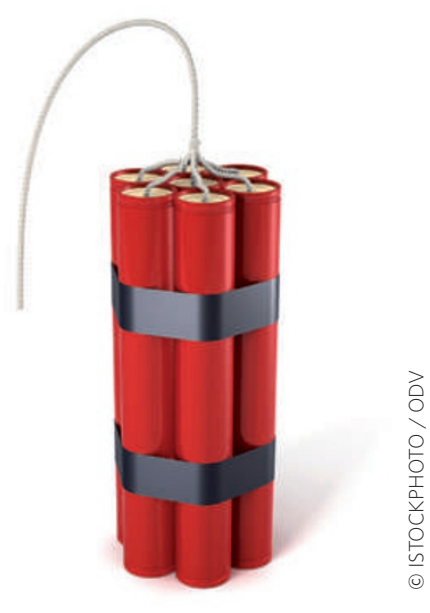

The effect of receiving the Nobel Prize on the careers of new laureates - and perhaps those who miss out - can be as explosive as Alfred Nobel's famous invention.

of a single prize to only three, to people still living, and the selection of those judged 'senior' in the discovery. One of the most infamous cases is that of Rosalind Franklin, whose X-ray photographs suggesting DNA's double helix provided others with the eureka moment, but who died four years before the award of the prize for the molecular structure of nucleic acids. It is perhaps surprising to see that Wikipedia's Nobel Prize controversies page ${ }^{3}$ is longer than that on the prize itself.

Being awarded the prize is not without its drawbacks, especially with the increased attention and demands on laureates' time. The prospect of such attention led Paul Dirac (Physics, 1933), an intensely private man, to consider turning down the prize, but it was suggested that this would generate more publicity than accepting it $^{4}$. Furthermore, elevation to the status of Nobel Laureate gives enough extra weight to their opinions - any opinions - that the temptation to use that status to further causes close to the heart must be strong. Even such a revered figure as chemistry laureate Linus Pauling (1954), it could be argued, had mixed results: his campaign to stop nuclear testing resulting in another Nobel Prize (Peace, 1962), whereas his work on vitamin $C$ was not accepted by the medical establishment.
Richard Ernst (Chemistry, 1991) said "After I won a Nobel Prize I suddenly turned into an omniscient sage, whereas formerly I was simply a workaholic"5. Richard Feynmann (Physics, 1965) also recognized this, commenting 6 "I believe that a scientist looking at non-scientific problems is just as dumb as the next guy".

It has been said that the history of the Nobel Prize is the history of science. This may be true, but only to the extent that history itself is written as the story of the monarchs and generals - in other words, ignoring the story of everyday people who make up the bulk of the population. Indeed, Tolstoy addresses this in War and Peace ${ }^{7}$, calling for historians to develop a technique to 'integrate' the contribution of individuals.

Science in Alfred Nobel's time was a pursuit of individuals, and not many of them either. A handful of corresponding enthusiasts based predominantly in Europe and North America is a far cry from the worldwide endeavour of modern research groups. Giving a prize to all the people who have contributed to a scientific advance - integrating the curve of work from summer students to group leaders - would be fairer, but less likely to generate easily digestible headlines.

And that is where the Nobel Prize is of great benefit to science - rather than individual scientists. The day of the Nobel Prize in Chemistry announcement is the one day of the year that chemistry is guaranteed to generate headlines, and positive ones at that.

So that is why we should care about the deliberations of Gunnar von Heijne, Astrid Gräslund, Måns Ehrenberg, Sven Lidin, Lars Thelander and Håkan Wennerström before they decide who to give the gold medallion(s) to this year. It is a global showcase for chemistry, and our subject deserves to have laureates we can all be proud of.

\footnotetext{
References

1. http://nobelprize.org/alfred_nobel/will/index.html

2. http://www.baesystems.com/Businesses/LandArmaments/ Divisions/BAESystemsAB/Divisions/Bofors/index.htm

3. http://en.wikipedia.org/wiki/Nobel_Prize_controversies

4. Feldman, B. in The Nobel Prize: A History of Genius, Controversy and Prestige 155 (Arcade, 2001).

5. http://www.scienceblogs.de/lindaunobel/2009/06/so-what-didyou-do-after-you-won-a-nobel-prize.php

6. Feynmann, R. P. The Pleasure of Finding Things Out (Perseus, 1999). 7. Ahearn, S. T. Am. Math. Monthly 112, 631-637 (2005).
} 